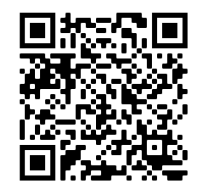

Keywords:

Artificial neural network

Strength

Mass loss

Press temperature Fire retarding agent

Panel

Historic: Received 24/01/2020 Accepted 26/06/2020

+Correspondence: mortezal7172000@yahoo.com
Morteza Nazerian ${ }^{\text {la+ }}$, Sakine Shirzaii ${ }^{2}$, Rahim Mohebbi Gargarii' ${ }^{2 a}$, Elham Vatankhah ${ }^{\text {lb }}$

\section{EVALUATION OF MECHANICAL AND FLAME RETARDANT PROPERTIES OF MEDIUM DENSITY FIBERBOARD USING ARTIFICIAL NEURAL NETWORK}

NAZERIAN, M.; SHIRZAII, S.; GARGARII, R. M.; VATANKHAH,E. Evaluation of mechanical and flame retardant properties of medium density fiberboard using artificial neural network.

CERNE, v. 26, n. 2, p.279-292, 2020.

\section{HIGHLIGHTS}

The ANN prediction model is a quite effective tool for modeling properties of MDF.

At a low press temperature, the negative effect of the fire retarding agents was maximum.

A reverse relation was observed between the changes in the mass loss of the fiberboard during the firing test and the MOR.

Improvement in properties of MDF can be achieved by the less experiments.

\section{ABSTRACT}

The present study presents the application of artificial neural network (ANN) to predict the modulus of rupture (MOR) and mass loss $(M L)$ of the fire retarded fiberboard. Hence, the effect of adding the fire retardants including boric acid, borax and ammonium sulfate was evaluated on MOR and ML of fiberboard manufactured at different press temperatures. At first, the experimental design was created based on the Response Surface Methodology, and then the significance of each independent variable with respect to its effect on the responses was evaluated through ANOVA test. It was determined that the positive effects of increasing press temperatures on MOR compensated the negative effects of fire retardant content on it. However, ML decreases more at the same time. ANN results exhibited a good agreement with experimental results. It was shown that the prediction error was in an acceptable range. The results indicated that the developed ANN model can predict the MOR and ML of the fiberboard with an acceptable accuracy. Therefore, applying the proposed model can lead to obtain the desirable outputs of MOR and ML by performing fewer experiments, and spending less time and cost. 


\section{INTRODUCTION}

It is for a long time that the application of MDF is popular for internal uses of buildings. However, flammability properties of this panel are still an important barrier to develop its application in different fields. Hence, actions must be taken in this regard to reduce flammability properties. However, like most wood-based composites, fire retardants can affect physical and mechanical properties of the fiberboard. Meanwhile, factors such as wood species, press conditions, type of treatment and type of the fire retarding chemical largely affect the panel's properties. The main fire retardants used in woodbased composites include mineral compounds such as phosphoric acid, mono-and di-ammonium phosphate, boron-compounds including borax, boric acid, etc. Like phosphorus-based salts, these materials are the oldest and the most common fire retardants that could play their role in wood-based panels (Winandy and LeVan, 1990; Ma et al., 2013; Mantanis et al., 2019). Creating the highest level of charcoal during burning among many compounds, these salts have the highest effect on fire retardant composites (Winandy and LeVan, 1990). In fact, these compounds affect the flammability by forming a carbon layer. Such a layer blocks the surface access to oxygen and temperature and prevents it from firing. Also, it reduces the release of flammable gases (Ozdemir and Tutus, 20I3). Battegazzore et al. (2018) showed that the mass loss in the fiberboard can be reduced and the access of the surfaces to oxygen can be decreased by forming a carbon layer on the surfaces of lignocellulosic fibers due to the presence of fire retardants such as ammonium phosphate. At the same time, it was known that the amount of the fire retardant also significantly affects the fire retarding properties of the board (Loredo and Bermejo, 2016). As the properties of resistance of the fiberboard against fire improve with the application of the fire retardants, the strength properties of the board are affected. The board's strength can be affected differently as a result of the physical and chemical changes created in the structure and chemistry of the cell wall of the wood (Winandy, 200I), acceleration or deceleration of resin coagulation by reducing or increasing $\mathrm{pH}$ in the resin solution (Winandy and River, 1986; Uner and Olgun, 2017) and contamination of the fibers' surface due to the presence of crystalline deposits loosely connected with fire retardantsin the glue line that can interfere with a suitable fiber-fiber contact (Arsenault, 1964). If the salts are in the interface of resin and fiber, separation under stress can be expected (Ayrilmis, 2007). Some fire retardants such as ammonium sulfate can dissolve in water, but some others such as borax remain only as a powder on the fibers' surface and increase the specific surface area in the mat and reduce the strength (Ayrilmis, 2007). Acidic fire retarding agents such as boric acid or phosphoric acid can also affect mechanical properties via increasing the panel's brittleness through depolymerization of long molecular polymers of cellulose, especially hemicellulose (Ayrilmis, 2007). This decrement is probably due to the brittleness of wood fibers created by the formation of crystals inside the cell walls of the wood or cross connections between cellulose or hemicellulose molecules (Bayani et al., 2019). These acidic fire retarding compounds largely decrease the length of the cellulose molecule and increase the level of charcoal (Winandy and LeVan, 1990; Wang et al. 2004). When the composite's surface is exposed to a high temperature, boric acid and borax make the flame disappear and prevent it from spreading (Yang and Qing, 20l4; Uner et al., 2016). These materials work through a low melting point and formation of a glassy film layer on the surface of these materials. In fact, borax acts by preventing the spread of flames, while boric acid increases carbonization. Hence, the combination of these two fire retarding agents can be used to obtain synergistic improvement in fire ret ardency (Baysal, 2002).

In addition to the additives such as fire retardants that can differently affect the fiberboard's properties, the press conditions also significantly affect the efficiency of the fiber components connected with resin (Ferle et al., 2018). It can be said that the press temperature is a very important part of the adhesion process and the resin curing. In the presence of fire retarding agents, the increase in the temperature may lead to the development or nondevelopment of the connection strength depending on improvement level of diffusion process which leads to an effective absorption of solution (Bekhta et al., 2016) and the change in the production capacity due to less press time required and completion of the resin curing process (Iswanto et al., 20I3). On the other hand, the excessive increase in the press temperature can decrease the strength of the fiber components. Therefore, press time can be increased as an alternative way to the higher press temperature to guarantee complete curing of the resin (Winandy and Krzysik, 2007). However, increasing either press temperature or press time significantly increases the thermal energy required for press operation and decreases the volume of production per unit time. Hence, the press conditions and panel efficiency must be balanced and this balance must be found permanently. Reaching this balanced point through experimental studies requires a large amount of time, cost, and raw materials. Hence 
recently, the studies on the prediction of the board's properties using modeling tools are preferred to common experimental instructions.

ANNs can process information in a parallel distributed method, train the complicated cause and effect relation between input and output data, deal with nonlinear problems and generalize known examples or tasks to unknown tasks. ANNs are good methods for cases including a set of incomplete data and offering incomplete fuzzy information and for problems with high complexities where people usually make decisions based on intuition (Boga et al., 2013).

An artificial neural network can provide an opportunity to achieve and determine the desirable values from the physical and mechanical properties of the fiberboard by doing less experimental studies due to its ability to detect the complexity and nonlinear relation in the information structure obtained (Reis et al., 2018). It can be stated that ANN models are very helpful to improve the processes of fabrication and to increase the strength of the fiberboards. Therefore, ANN techniques were used in several studies to predict the strength and physical properties of wood-based products and lignocellulosic materials. For exemple, Bardak et al. (2016), Palacios et al. (20I8), Andre et al. (2008), Bardak (20I8), and Watanabe et al. (20I5) used ANN methods to model the mechanical properties of the particleboard and fiberboard. Akyuz et al. (2017) also examined a similar method to model the formaldehyde emission.

Most of these studies have examined the bondability, bending strength or physical properties. To the best of our knowledge, ANN techniques are not used to study and predict the properties of the fire retardant fiberboard in presence of different fire retarding agents. In the related resources, the effect of the additives and variables related to the production process was discussed on the physical and mechanical properties of the particleboard and fiberboard in detail. In addition, ANN tried to predict these properties both in woodbased composites and massive wood. In fact, ANNs are a branch of artificial intelligence and focus on modeling and optimization. The structure and functionalization of this modeling technique are based on the biological brain activity and this is achieved by training from the test results and extracting knowledge from it. This analysis is achieved by the results of a test from some nodes called neurons that are organized in several layers depending on the type of ANN. The type of the neural network that is mainly used to model the mechanical properties is the multilayer perceptron (MLP). MLP's nature as an approximating function has made it a powerful tool, especially when obtaining a very reliable solution is more important than determining the relation between the variables involved in the process (De Veaux and Ungar, 1996). There are a little or no information on the study and prediction of the effects of different fire retarding compounds and their interaction with the process variable of fiberboard production on the fire retarding behaviors and mechanical properties of medium density fiberboard using ANN as a new method. Therefore in the present research, it is tried to show capability of ANN approach in order to predict the bending strength and fire retarding property of MDF fire-retarded with adding different fire retarding agents including boric acid, borax and ammonium sulfate as the press temperature is changed.

\section{MATERIALS AND METHOD}

The fibers required for making the fiberboard were prepared from the industrial wood species fibers produced in Khazar Amol MDF factory, Mazandaran Province, Iran. After being transferred to the laboratory of Zabol University and keeping their moisture at the point of equilibrium with the environment $(\sim 5-6 \%)$ by a laboratory oven dryer, the fibers were put into plastic bags to make their moisture constant. Urea formaldehyde resin with a concentration of $62 \%$ used in this study was produced in Samed adhesive producing company, Mashhad, Iran (Table I).

TABLE I Characteristics of urea formaldehyde resin.

\begin{tabular}{ccccc}
\hline $\begin{array}{c}\text { Density } \\
\left(\mathrm{kg} \cdot \mathrm{m}^{-3}\right)\end{array}$ & $\begin{array}{c}\text { Solid } \\
\text { materials } \\
(\%)\end{array}$ & $\begin{array}{c}\text { Viscosity } \\
(\mathrm{CP})\end{array}$ & $\begin{array}{c}\text { Gel time } \\
(\mathrm{s})\end{array}$ & $\mathrm{pH}$ \\
\hline 1275 & 50 & $200-400$ & 55 & 7.6 \\
\hline
\end{tabular}

Independent variables include boric acid at five levels $(0,1.5,3,4.5,6 \%)$, borax at five levels $(0$, I.5, 3, 4.5, 6\%), ammonium sulfate at five levels $(0$, I.5, 3, 4.5, 6\%) and press temperature at five levels $\left(135,150,165,180\right.$ and $\left.195 \mathrm{C}^{\circ}\right)$. The dependent variables measured include modulus of rupture (MOR) and mass loss (ML) of the fiberboard during the flammability test. The second order plan statistical design and Expert Design Software ver. 6 were used to determine the significance of the direct effects, squared effects, and mutual effects of the independent variables of the study on MOR and ML as dependent variables. The number of fabrication conditions and levels of the variables in each fabrication condition are given in Table 2. 
TABLE 2 Independent variables, their levels, actual and estimated values of dependent variables, and the mean percentage error indicating the accuracy of predicted values usingANN compared to actual values..

\begin{tabular}{|c|c|c|c|c|c|c|c|c|c|c|}
\hline & 1 & $\times 2$ & $\times 3$ & $\times 4$ & \multicolumn{3}{|c|}{ MOR (MPa) } & \multicolumn{3}{|c|}{ Mass loss, \% } \\
\hline & & & & & Tar. & Out. & Err. & Tar. & Out. & Err. \\
\hline T & 165 & & 88 & 3.88 & 17 & & & 1.55 & & 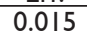 \\
\hline 2 & & & & & 13 & & & 0.6 & & \\
\hline 3 & 180 & & & & 17 & & & 1.59 & & 40 \\
\hline 4 & 19 & 3.8 & & & 21 & & & 1.7 & & \\
\hline 5 & 18 & & & & 17 & & & 1.44 & & \\
\hline 6 & 15 & & & & 12 & & & 0.85 & & \\
\hline 7 & 150 & & & & 21 & & & 65 & & \\
\hline 8 & 13 & & & & 13 & & & 38 & & \\
\hline 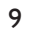 & & & & & 8 & & & 0.49 & & \\
\hline & 16 & & & & 16 & & & 1.56 & & \\
\hline & 10 & & & & 19 & & & 1.49 & & \\
\hline 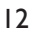 & & & & & 10 & & & .22 & & \\
\hline 3 & 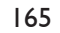 & & & & 19 & & & 1.55 & & \\
\hline & 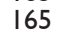 & & 3.8 & & 15 & & & 1.5 & & \\
\hline 5 & & & & & 17 & & & 1.53 & & \\
\hline 6 & & & & & 17 & & & & & \\
\hline & 16 & & 3. & & 17 & & & 1.8 & & \\
\hline & & & & & 8 & & & 0.68 & & \\
\hline 19 & & & & & 1 & & & & & \\
\hline & 18 & & 5.8 & & 13.7 & & & 1.25 & & \\
\hline & I & & & & 0 & & & .88 & & \\
\hline & & & & & 12.9 & & & & & \\
\hline & & & & & 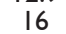 & & & 1.49 & & \\
\hline 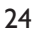 & & & & & 16.5 & & & 1.5 & & \\
\hline & & & & & IC & & & & & \\
\hline 26 & & & & & 2 & & & & & \\
\hline 57 & & & & & 12 & & 0. & 0.65 & & \\
\hline 28 & & & & & 12 & & & & & \\
\hline 2 & & & & & 12 & & & 0. & & \\
\hline 30 & & & & & 16 & & 0.38 & 1.07 & .1028 & -0.03 \\
\hline
\end{tabular}

To prepare the specimens, the dried fibers were first weighed by a digital scale with the precision 0.05 gr and were mixed with resin in a laboratory adhesive blender. The required amounts of the fire retardants were added to the resin solution according to Table 2, and they were stirred for $20 \mathrm{~min}$ in the mixer until they were dissolved/ dispersed well in the resin. Afterwards, the resin mixture was sprayed on the fibers (with $5 \%$ moisture) inside the rotating adhesive blender, and they were mixed for 5 minutes. After being mixed completely, the mixture of resin and fibers was put manually into a wooden mold and was distributed uniformly. After removing the mold, the fibers' mat was put into a laboratory press. The final moisture of the mat was set at $12 \%$. Some important constant factors of the fabrication of the fiberboard included: pressure of $3 \mathrm{MPa}$, press time of $9 \mathrm{~min}$, press closing time of $4.5 \mathrm{~mm}$ min-I, final board thickness of $16 \mathrm{~mm}$, final board density of $750 \mathrm{~kg} / \mathrm{m} 3$, adhesive concentration of $62 \%$, and resin's dry weight to the total board's dry weight ratio of $12 \%$.

The test boards made in the laboratory conditions were put in the climatization chamber for two weeks at the relative humidity of $65 \%$ and the temperature of 20 $2 \mathrm{C} \pm{ }^{\circ}$ to reach the equilibrium condition. To determine the MOR, the test specimens were then cut at the specific dimensions according to EN 326 - I standard and were exposed to the static bending and mass loss tests according to EN 310 (1993) and ISO II925-3 (1997) standards, respectively.

To determine the efficiency of fire retardants, samples were exposed to the flame and their mass loss percentage was measured. The experiment was carried out in triplicate for each treatment. In this regard, after being climatized, each board was weighed and a specimen with dimensions of $140 \mathrm{~mm} \times 70 \mathrm{~mm}$ and the angle of $35^{\circ}$ was installed on a laboratory clamp fixed in a chamber with metal walls where a spirit lamp was turned on and put under the specimen with the flame height of $55 \mathrm{~mm}$. The distance between the flame and the specimen was $10 \mathrm{~mm}$ and the test time was $150 \mathrm{~s}$. A chronometer was used to record the time of the firing point and durability of firing after removing the nozzle. When the test finished, the specimen was weighed and the mass loss percentage due to the burning was calculated based on the following equation I, where, $M L$ is the mass loss percentage and $\mathrm{W}(\mathrm{t})$, and $\mathrm{W}(\mathrm{o})$ are the specimen's weight before fire test and dry weight of the specimen after fire test, respectively.

$\operatorname{ML}(t)=\frac{W_{(t)}-W_{(o)}}{W_{(x)}} \times 100$

To create the experimental design and determine the number of treatments for making the test specimens and finally to analyze the MOR results and ML of the boards, the response surface method (RSM) and CCRD (central composite rotatable design) matrix were used with the points at the center of any axis of the factorial space. The total number of the tests required for four independent variables is $42(4 * 2) 630++=$ based on the equation $2(* 2) \mathrm{n} \mathrm{nk}++$ where $\mathrm{n}$ is the number of variables and $\mathrm{k}$ is the number of repetitions at the center of the matrix cube (Manonmani et al., 2007). The experimental design used to produce the board is given in Table 2. An artificial neural network (ANN) was utilized to predict and determine the optimal point for producing the fire retardant fiberboard. Any neural network includes an internal neuron layer as the inputs of the system, an external neuron layer as the outputs of the system and one or more intermediate or hidden neuron layers (Fig. I). While the number of neurons in the first and last layers of the neural network depends on the number of input and output parameters of the system, the number of neurons in the intermediate layers depends on the designer's opinion and correctness of the outputs obtained with the actual output parameters of the system. The number of intermediate layers is normally one layer or it is two layers in special cases, and more than two layers are rarely used and are not recommended. Neural networks are powerful tools to model nonlinear statistical data and can be used to model the complicated relations between the inputs and outputs or find the data patterns (Guoliang et al., 20l0). 


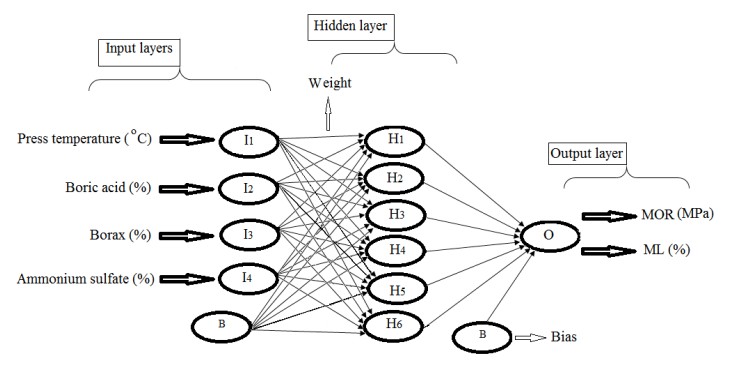

FIGURE I An ANN architecture used to compute fiberboard parameters.

To create the experimental design and determine the number of treatments for making the test specimens and finally to analyze the MOR results and ML of the boards, the response surface method (RSM) and CCRD (central composite rotatable design) matrix were used with the points at the center of any axis of the factorial space. The total number of the tests required for four independent variables is 42 ( 4* 2 )6 $30++=$ based on the equation 2 ( * 2 ) $n \mathrm{nk}++$ where $\mathrm{n}$ is the number of variables and $\mathrm{k}$ is the number of repetitions at the center of the matrix cube (Manonmani et al., 2007). The experimental design used to produce the board is given in Table 2. An artificial neural network (ANN) was utilized to predict and determine the optimal point for producing the fire retardant fiberboard. Any neural network includes an internal neuron layer as the inputs of the system, an external neuron layer as the outputs of the system and one or more intermediate or hidden neuron layers (Fig. I). While the number of neurons in the first and last layers of the neural network depends on the number of input and output parameters of the system, the number of neurons in the intermediate layers depends on the designer's opinion and correctness of the outputs obtained with the actual output parameters of the system. The number of intermediate layers is normally one layer or it is two layers in special cases, and more than two layers are rarely used and are not recommended. Neural networks are powerful tools to model nonlinear statistical data and can be used to model the complicated relations between the inputs and outputs or find the data patterns (Guoliang et al., 2010).

$M S E=\frac{1}{n} \sum_{i=1}^{n}(E i-P i)^{2}$

Hence, the neural network used in this study received three inputs of fire retardants including ammonium sulfate, boric acid and borax and the press temperature as the forth input while MOR and ML were considered as outputs of the ANN models.

All input and output data used for the neural network include 90 data that were chosen from diagrams of press temperature - MOR and press temperature ML between the temperatures from 135 to $195 \mathrm{C}$ with the distance of $15{ }^{\circ} \mathrm{C}$. Among all data, $70 \%$ were used for training the network, 15\% were used for validating the network and $15 \%$ were used for testing the predictability of the trained network. In the neural network, transfer functions are normally used as the activation functions for the hidden layers, such as tan sigmoid function or log sigmoid function. However, the linear transfer function can be used for output neurons (Wu et al., 200I; Phaniraj and Lahiri, 2003). Tan sigmoid and log sigmoid functions range from - I to I and I to 0, respectively, and they can be expressed as the equations (3) and (4). In this network, a tan sigmoid function is used as the transfer function in the hidden layers and a linear function is used in the output layer.

$$
\begin{aligned}
& f=\tan \operatorname{sig}(x i)=\frac{\exp (x i)-\exp (-x i)}{\exp (x i)+\exp (-x i)} \\
& f=\log \operatorname{sig}(x i)=\frac{1}{1+\exp (-x i)}
\end{aligned}
$$

Toolbox of MATLAB 15 Software was used to develop the neural network.

\section{RESULTS AND DISCUSSION}

The number of treatments was chosen as 30 for this analysis (Table 3 ) based on the reference (Manonmani et al., 2007).

\begin{tabular}{|c|c|c|c|c|c|c|c|}
\hline Source & Response & S.S. & Df & M. S. & F Value & Prob $>F$ & Sig. \\
\hline \multirow{2}{*}{ Model } & MOR & 436.1 & II & 39.64 & 27.35 & $<0.01$ & **⿻丷木 \\
\hline & M. loss & 4.46 & 9 & 0.50 & 217.80 & $<0.01$ & **⿻丷木 \\
\hline \multirow{2}{*}{ XI } & MOR & 48.12 & I & 48.12 & 33.20 & $<0.01$ & **⿻丷木 \\
\hline & M. loss & 0.20 & 1 & 0.20 & 88.74 & $<0.01$ & *** \\
\hline \multirow{2}{*}{$\times 2$} & MOR & 33.94 & I & 33.94 & 23.42 & $<0.01$ & **⿻丷木 \\
\hline & M. loss & 0.49 & $\mathrm{I}$ & 0.49 & 214.63 & $<0.01$ & *** \\
\hline \multirow{2}{*}{$\times 3$} & MOR & 42.48 & I & 42.48 & 29.31 & $<0.01$ & *** \\
\hline & M. loss & 0.12 & I & 0.12 & 54.55 & $<0.01$ & *** \\
\hline $\mathrm{X4}$ & M. loss & 0.011 & $\mathrm{I}$ & 0.011 & 4.73 & 0.0418 & * \\
\hline \multirow{2}{*}{$\times 2^{2}$} & MOR & 18.88 & I & 18.88 & 13.02 & 0.002 & *** \\
\hline & M. loss & 0.18 & I & 0.18 & 79.61 & $<0.01$ & *** \\
\hline \multirow{2}{*}{$\times 3^{2}$} & MOR & 13.56 & I & 13.56 & 9.36 & 0.001 & *** \\
\hline & M. loss & 0.17 & I & 0.17 & 72.52 & $<0.01$ & **⿻丷木 \\
\hline$\times 4^{2}$ & M. loss & 0.54 & I & 0.54 & 238.70 & $<0.01$ & *** \\
\hline$X 1 \times 2$ & MOR & 6.47 & I & 6.47 & 4.47 & 0.0488 & * \\
\hline $\mathrm{XI} \times 3$ & M. loss & 0.012 & I & 0.012 & 5.31 & 0.0321 & * \\
\hline$\times 2 \times 3$ & MOR & 37.05 & I & 37.05 & 25.56 & $<0.01$ & *** \\
\hline$\times 2 \times 4$ & M. loss & 0.027 & I & 0.027 & 11.95 & 0.0025 & *** \\
\hline$\times 3 \times 4$ & MOR & 6.47 & I & 6.47 & 4.46 & 0.0489 & * \\
\hline MOR & Lack of Fit & 23.21 & 13 & 1.79 & 3.11 & 0.1091 & not sig. \\
\hline M. loss & Lack of Fit & 0.041 & 15 & 0.00275 & 3.21 & 0.1016 & not sig. \\
\hline
\end{tabular}

TABLE 3 Analysis of variance (ANOVA)

Based on the output of the variance analysis (Table 3), it is observed that the model used is significant for MOR and mass loss responses. The direct effect of the independent variables including the press temperature $\left(x_{1}\right)$, boric acid $\left(x_{2}\right)$, borax $\left(x_{3}\right)$ and ammonium sulfate $\left(x_{4}\right)$ is significant on the mass loss statistically, while the effect of $x_{4}$ is not significant on MOR. Also, the squared effects of $x_{2}$ and $x_{3}$ are significant both on MOR and mass loss, while the squared effect of $x \mathrm{I}$ is not significant on MOR and mass loss. In addition, the squared effect of $x_{4}$ is significant only on mass loss, and it is not significant on MOR. Furthermore, it is observed that the mutual effects of $x_{1} x_{2}, x_{2} x_{3}$ and $x_{3} x_{4}$ are significant on MOR, and those of $x_{1} x_{3}$ and $x_{2} x_{4}$ are significant on mass loss statistically, and other mutual effects are not significant on the responses being examined. 
To produce valid prediction of output datasets from targets, an ANN was employed to analysis effect of assumed variables on MOR and ML of fiberboard. To determine the number of neurons in the hidden layer, 6 neurons were finally considered in this layer after following the method of trial and error and repetition in the training of the network by changing the number of neurons from 0 to 20 in the hidden layer. In this condition, the network showed the best performance, so that as the number of neurons decreased or increased in the hidden layer, the efficiency of the network decreased, and the network did not learn. The comparison between experimental results from the experiment and predicted results by the neural network is given in Figs. $2 \mathrm{a}$ and $3 \mathrm{a}$ for the fiberboard. The results indicate that the prediction of the neural network from the training datasets (Fig. $2 \mathrm{~b}$ and $3 \mathrm{~b}$ ) is acceptable in a wide range of data. The predicted data by the neural network show the bending behavior and mass loss of the fiberboard with different values of the fire retardantscured at different press temperatures well. Also, the suitable ability of the neural networks to predict the static bending behavior and mass loss of the panel is observed, so that at the all ranges of press temperatures, $140-200 \mathrm{C}^{\circ}$, and amount of added fire retarding agents as $1.5 \%$, the bending behavior and mass loss are predicted well with the lowest error.

According to Fig. 2 and 3 , it is evident that there is a high correlation and fitness between the test and predicted values and it shows that the ANN model used has proved its efficiency to predict the bending behavior and mass loss of the fiberboard.
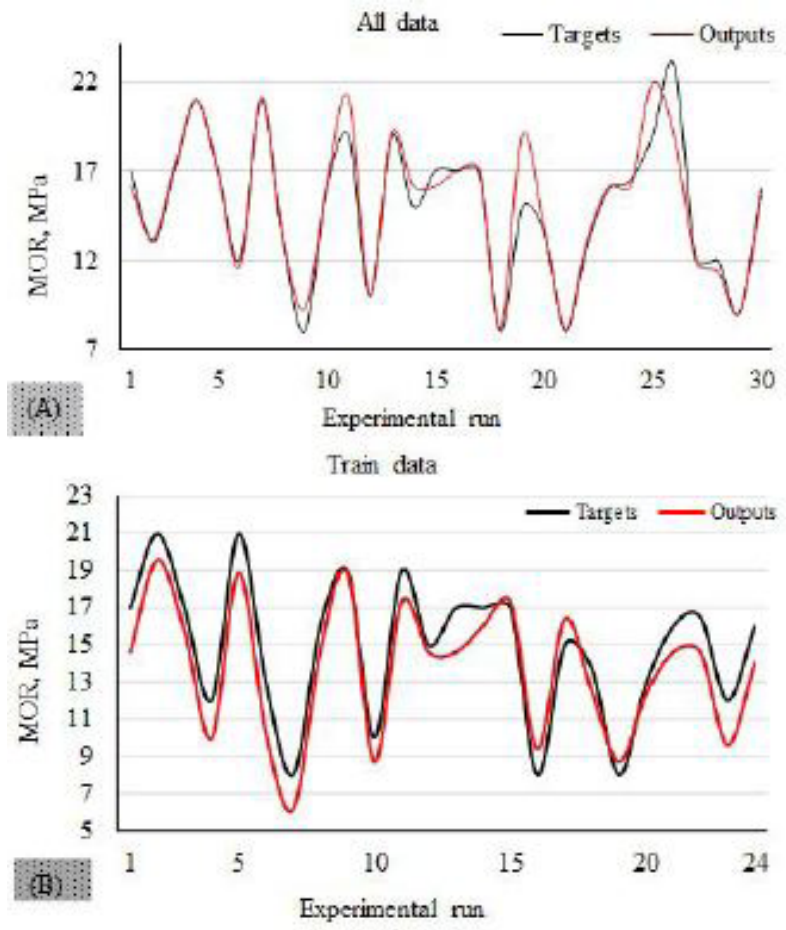

FIGURE 2 Comparison between the target (actual) and output (estimated) values for (A) all data and (B) train data for MOR.

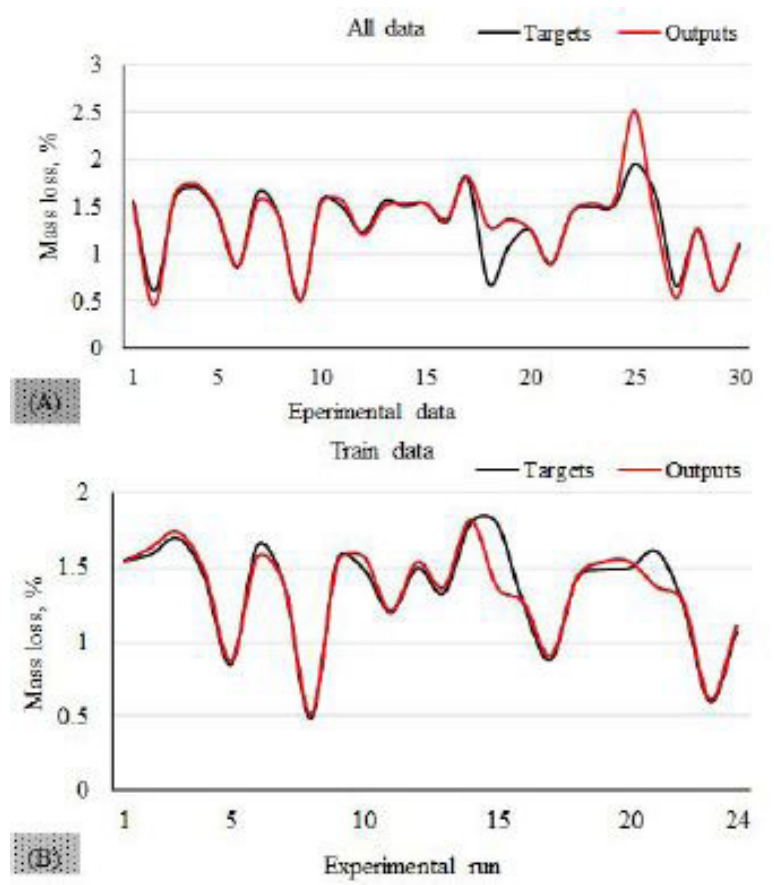

FIGURE 3 Comparison between the target (actual) and output (estimated) values for $(A)$ all data and $(B)$ train data for ML.

After observing the suitable performance of the neural network, the network is used to develop, estimate, and analyze the outputs of the neural network, i.e. MOR and mass loss of the fiberboard made under the press with a similar temperature. The values of MOR and mass loss predicted by ANN model for specimens with different contents of fire retardants $(0 \%, 1.5 \%, 3 \%$, $4.5 \%$ and $6 \%$ ) and cured at different temperatures from 135 to $195 \mathrm{C}^{\circ}$ are presented in Figs. 4 and 5, respectively.

According to Fig. 4A, the results of the artificial neural network show that MOR values decreased as the fire retarding agent "boric acid" increased up to $6 \%$ at all ranges of the press temperature. Also, as the temperature increased from $135 \mathrm{C}^{\circ}$ to $195 \mathrm{C}^{\circ}$, MOR increased at all ranges of the consumed boric acid and the negative effect of adding boric acid as the fire retarding agent decreased. These results are obtained when the values of other fire retarding agents including borax and ammonium sulfate were minimum (i.e. $0 \%$ ). The diagrams show that the changes in MOR almost follow a stable uniformity.

According to Fig. 4B, adding borax from 0 to $1.5 \%$ results in a decrease in MOR as the temperature increases from $135 \mathrm{C}^{\circ}$ to $195 \mathrm{C}^{\circ}$, and at the level of $3 \%$, the changes in the temperature do not affect the MOR value (also according to Table 2). However, adding borax from 4.5 to $6 \%$ increases this property as the press temperature increases. These results are obtained when the values of other fire retardants content in the fiberboard including boric acid and ammonium sulfate were minimum, i.e. $0 \%$. 

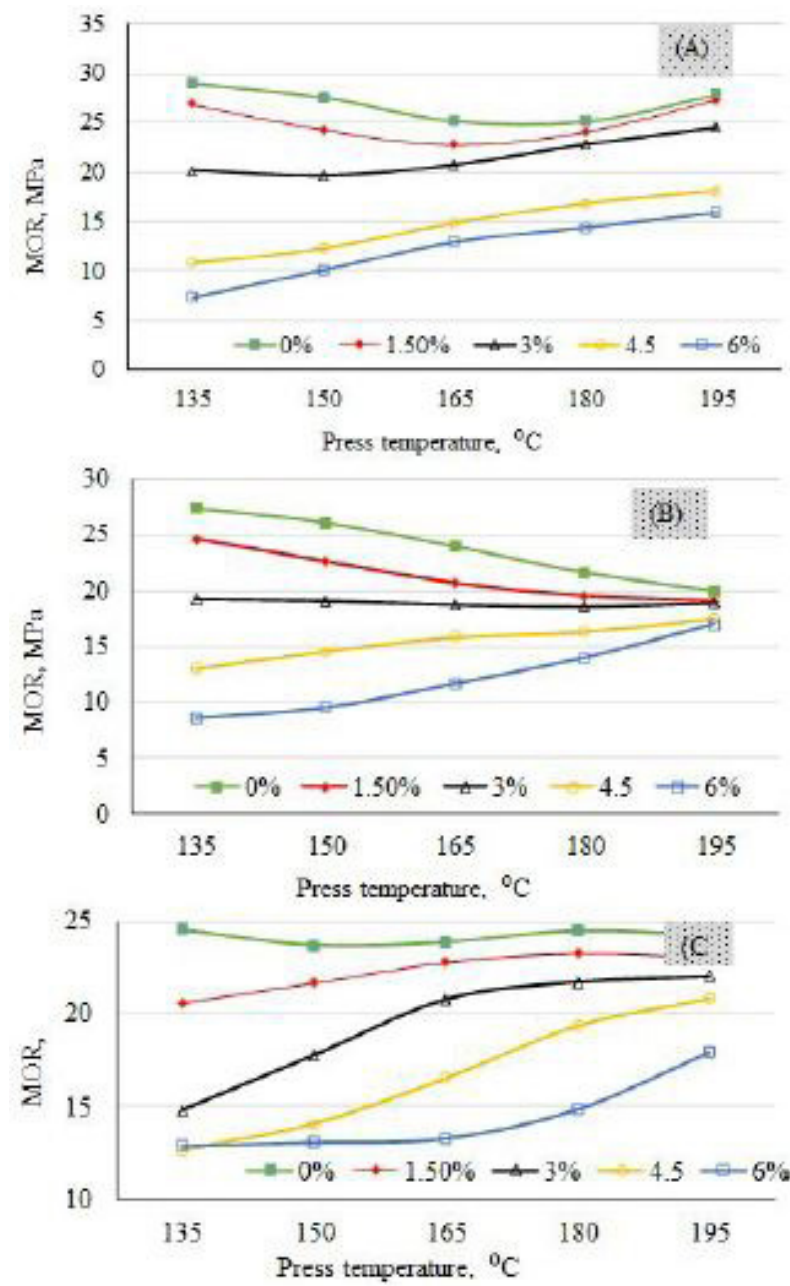

FIGURE 4 The change of MOR as a function of the press temperature together with the retardant agents: (A) boric acid, (B) borax and (C) ammonium sulfate at the minimum level of other fire retarding agents (the lines belong to the actual values and markers belong to the predicted values obtained by ANN).

According to Fig. $4 \mathrm{C}$, the changes in the press temperature do not affect the MOR, while adding ammonium sulfate from $1.5 \%$ to $6 \%$ decreases this property, and the increase in the press temperature at any range of the consumed ammonium sulfate results in an increase in MOR. The positive effect of the temperature was maximum when a maximum level of ammonium sulfate was used. This is when the consumption of other fire retarding agents including boric acid and borax in the fiberboard was minimum, i.e. $0 \%$.

In Fig. 5, the effect of press temperature on the ML of MDF specimens is presented in presence of different ranges of fire retardants contents from 0 to $6 \%$. According to ANOVA (Table 2), the independent effect of the press temperature, the type of the fire retardants and its value is significant on the ML. Also, according to this table, the squared independent effects and the mutual effects of any of the independent variables are significant on the ML. According to Fig. $3 \mathrm{~A}$, adding boric acid from 0 to $6 \%$ has decreased the $M L$ at all ranges of the consumed
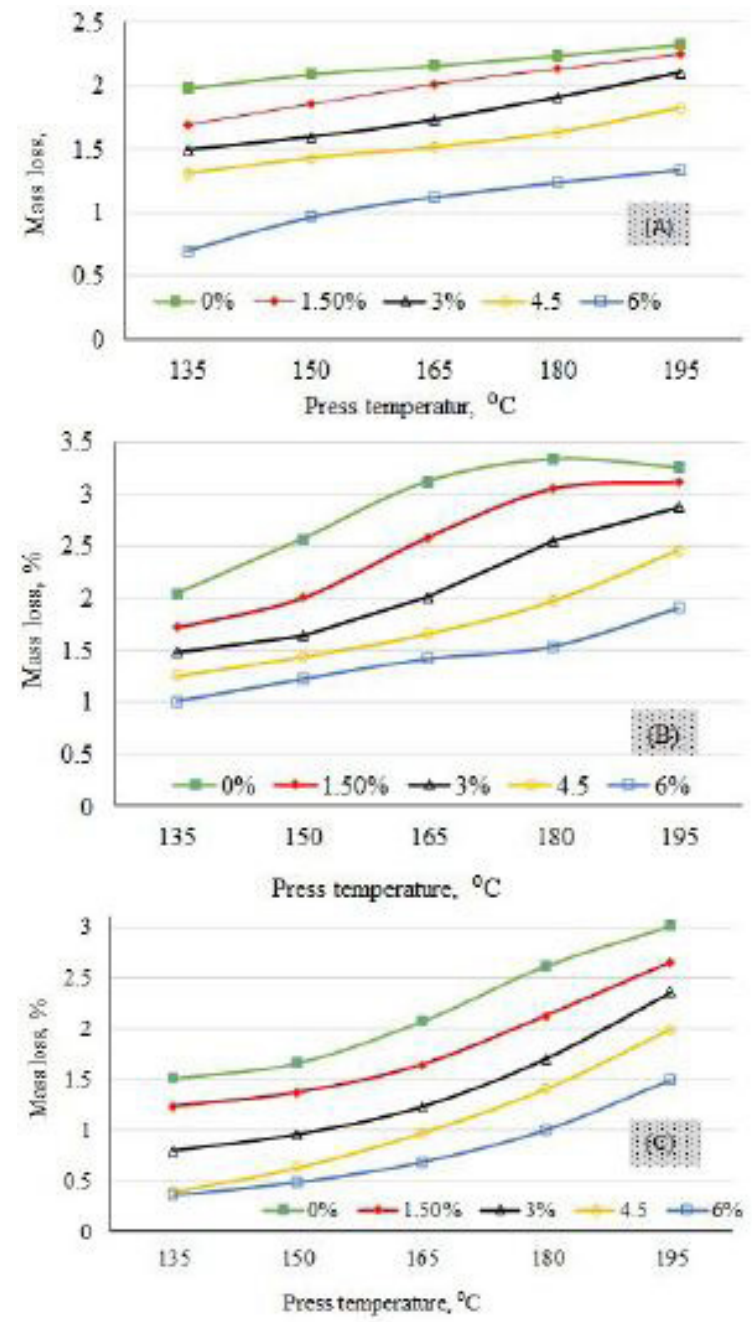

FIGURE 5 The change of the mass loss as a function of the press temperature together with the retardant agents: (A) boric acid, (B) borax and (C) ammonium sulfate at the minimum level of other fire retarding agents (the lines belong to the actual values and markers belong to the predicted values obtained by ANN).

fire retarding agent. Increasing the press temperature has increased the ML of the fiberboard at any range of the fire retarding agent during the flammability test. The highest level of $M L$, i.e. more than $2 \%$, is related to a specimen made at the highest press temperature $\left(195 \mathrm{C}^{\circ}\right)$ and containing the lowest level of the fire retardants, while the lowest level of $M L$, i.e. $1.2 \%$, is related to a specimen made at the lowest press temperature $\left(135 \mathrm{C}^{\circ}\right)$ and containing the highest level of the fire retardants. It is observed that the changes in the $M L$ are completely linear.

According to Fig. 5B, as the press temperature increases and the consumption of the fire retarding agent "borax" decreases, mass loss increases. On the contrary, as the level of the fire retardant "borax" increases and the press temperature decreases, mass loss decreases. It seems that as similar levels of boric acid and borax are used in a certain press temperature, the mass loss of the 
specimens containing borax is more and approaches $3 \%$. According to the Figs. $5 \mathrm{~A}$ and $5 \mathrm{~B}$, it is evident that the changes in the mass loss of the specimens follow a rather similar trend, although the addition of borax has made the curve a little parabolic.

According to Fig. 5C, the trend of the changes in the mass loss of the specimens containing ammonium sulfate is similar to the specimens containing boric acid and borax, so that as the temperature increases and the level of ammonium sulfate as a fire retardant decreases , the mass loss of the specimens increases. On the contrary, as the level of ammonium sulfate increases and the press temperature decreases, the mass loss of the specimens decreases. Generally, the changes in the mass loss of the specimens containing borax and ammonium sulfate are similar and are somewhat (significantly) less than the specimens containing boric acid. The trend of the changes of this response is almost similar as the press temperature and the level of different fire retarding agents being used change.

The predictability and performance of the neural network model are generally described by the correlation coefficient (R), Average Absolute Relative Error (AARE) and Root Mean Square Error (RMSE) that are defined as the following equations, where $\mathrm{Ei}$ is the experimental data, $\mathrm{Pi}$ is the data predicted by the neural network, and are the average values of the experimental data and the data predicted by the neural network, respectively, and $\mathrm{N}$ is the total number of the data of the study.

$R=\frac{\sum_{i=1}^{N}\left(E_{i}-\bar{E}\right)\left(P_{i}-\bar{P}\right)}{\sqrt{\sum_{i=1}^{N}\left(E_{i}-\bar{E}\right)^{2}} \sum_{i=1}^{N}\left(P_{i}-P\right)^{2}}$

$\operatorname{AARE}(\%)=\frac{1}{N} \sum_{i=1}^{N}\left|\frac{E_{i}-P_{i}}{E_{i}}\right| \times 100$

RMSE $=\sqrt{\frac{1}{N} \sum_{i=1}^{N}\left(E_{i}-P_{i}\right)^{2}}$

The correlation coefficient usually shows the linear relation between the predicted values and the experimental data. $R$ ranges from 0 to $I$ and if $R$ is close to $I$, it means that the linear regression of the data has a good fit. However, as $\mathrm{R}$ approaches 0 , the linear regression of the data is not a good fit. Hence, an equation may show the tendency toward higher or lower values. Therefore, higher $R$ values do not always show the better performance of the model. MAPE and RMSE are unbiased statistics to measure the predictability of a model, so that lesser MAPE and RMSE values are better. Table 2 shows the predictability of the neural network for the training and testing data. It can be concluded that these values of the training and testing data sets showed the ability of the used network in predicting studied responses. The predicted values and the percent of MOR and ML errors are given in Table 2 as a result of ANN analysis. The prediction of the neural network is very close to the measured values in most cases . In other words, it can be said that ANN analysis is capable to predict MOR and ML with a low error percentage.

The Table 4 shows RMSE and MAPE as indicators of the accuracy of the prediction It is well known that MAPE is used as the basic criterion to evaluate the performance of the proposed ANN model. MAPE values calculated ffor MOR of training, validation and test datasets were $0.4876 \%, 4.005$, and $1.9853 \%$, respectively.. The values of MAPE for ML of training, validation and test datasets were found $0.4560 \%, 4.005$, and $0.0345 \%$, respectively. Therefore, the MAPE values are less than $10 \%$ which is considered as acceptable for a prediction with a high accuracy.

TABLE 4 Capability of ANN model for estimating train and test.

\begin{tabular}{ccccccc}
\hline \multirow{2}{*}{ Data } & \multicolumn{2}{c}{ RMSE } & \multicolumn{2}{c}{ MAPE $(\%)$} & \multicolumn{2}{c}{ R } \\
\cline { 2 - 7 } & MOR & M. loss & MOR & M. loss & MOR & M. loss \\
\hline Training data & 0.1545 & 1.2055 & 0.4560 & 0.4876 & 0.96919 & 0.95721 \\
\hline Testing data & 0.0836 & 1.9914 & 0.0345 & 1.9853 & $0.9329 \mid$ & 0.96552 \\
\hline
\end{tabular}

According to the calculated RMSE values, accuracy in prediction of responses was very satisfactory. For MOR, RMSE was I.3033 for all datasets, I.2025 for the training dataset, I.9196 for the validation dataset and I.9914 for the testing dataset. For ML, RMSE was 0.1725 for all datasets, 0.1545 for the training dataset, I.4846 for the validation dataset and 0.0836 for the testing dataset. It can be stated that RMSE values close to 0 mean the better fit between the predicted and measured outputs (Canakci et al., 20I2). In sum, both MAPE and RMSE are in an acceptable range of accuracy for the testing, validation, and training stages.

The regression curves fitted to the training, validation, test datasets as well as to all data are shown in Figs. 6 and 7 for MOR and ML, respectively. As it can be seen $\mathrm{R}$ was found $0.9572 \mathrm{I}, 0.92554$, and 0.96552 for training, validation and test datasets of MOR, respectively and the curve fitted to all MOR data showed a correlation value of 0.921 17. Regression curves fitted to $M L$ data also showed $R$ values greater than 0.9 (training $R=0.96919$, validation $R=0.99899$, test $R=0.9329 \mathrm{I}$, and all $R=0.91882$ ). As the correlation coefficient $\left(R^{2}\right)$ approaches $\mathrm{I}$, the accuracy of the prediction increases, and it shows a desirable agreement between the experimental results and the model's prediction. According to $\mathrm{R}^{2}$ values, the obtained network can describe at least $93 \%, 91 \%, 85 \%$ and $84 \%$ of the test, training, validation and all dataset obtained for MOR, respectively, and $87 \%, 93 \%, 99 \%$ and $84 \%$ of the test, training, validation and all dataset obtained for ML, respectively. These values support the agreeability of the application of ANNs in this study. 

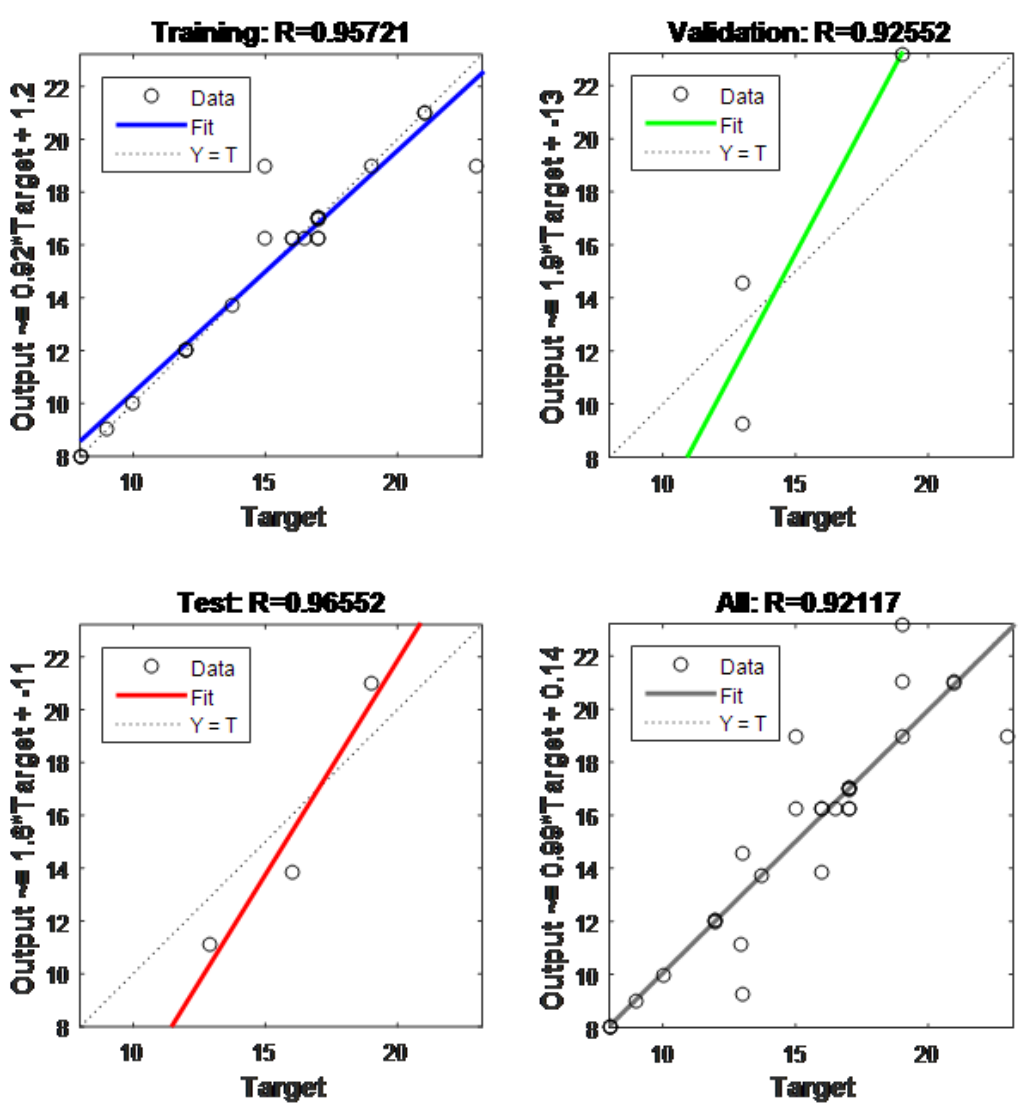

FIGURE 6 Relationship between experimental results and ANN predicted results for MOR.

The effect of the parameters of the study on MOR and $M L$ of the fiberboard is complicated and there are interdependencies. It is difficult to show the mutual effects of the parameters on MOR and ML by examining one factor. Hence, the mutual effects of the press temperature and different values of different fire retardants on MOR and $M L$ are presented as 3D diagrams (Figs. 8 and 9). The prediction model produced by applying the neural network in this figure predicts the test results with a high accuracy with no need to run further experiments. The effect of the temperature and the level of the fire retardants "boric acid" on MOR was analyzed (Fig. $8 \mathrm{~A}$ ) and it was observed that as the temperature increased from $145 \mathrm{C}^{\circ}$ to $185^{\circ}{ }^{\circ}$, the fiberboard's strength increased significantly. However, the increase in the temperature has increased the ML (Fig. 9A).

The increase in the $M L$ is reversely proportional to MOR. However according to the results obtained, it became evident that the increase in the $M L$ is accompanied by the increase in the MOR. The reason can be attributed to the dependency of MOR not only on the decrease in the ML but also on other related factors simultaneously.

The increase in the temperature results in an increase in the compaction ratio both in the surface layers and intermediate layers, and hence, it improves and increases the fibers' overlapping and creates a higher contact surface. As a result, stress can be transferred better from the surface under pressure to the layers under tension during the bending test, and the MOR increases. Also, as the level of the consumption of the fire retardants increases from 0 to $6 \%$, the strengths decrease continuously. As different fire retarding agents are added, the changes in the MOR are almost similar and follow a similar pattern. ccording to Fig. 8(A, B, and $C)$, a sharp decrease in MOR is observed by increasing the fire retardant content when the press temperature is minimum. Increasing the fire retardant content enhances the increasing effect of temperature on MOR. Therefore, the negative effect of fire retardant content on MOR is partially compensated. As a result, if the fire retarding agent is added up to $3 \%$ where the temperature is at maximum, the strengths not only will not decrease, but also will increase to the maximum level (about 2I MPa). However, if the fire retarding agent is added more than $3 \%$, a remarkable decrease in the MOR can be observed even at high press temperatures.

Adding borate to UF resin to connect the fibers together prevents from resin's coagulation. Using borates as fire retarding agents in the panel may create some problems. One of the most serious problems is related to its reverse effect on the mechanical properties of the 

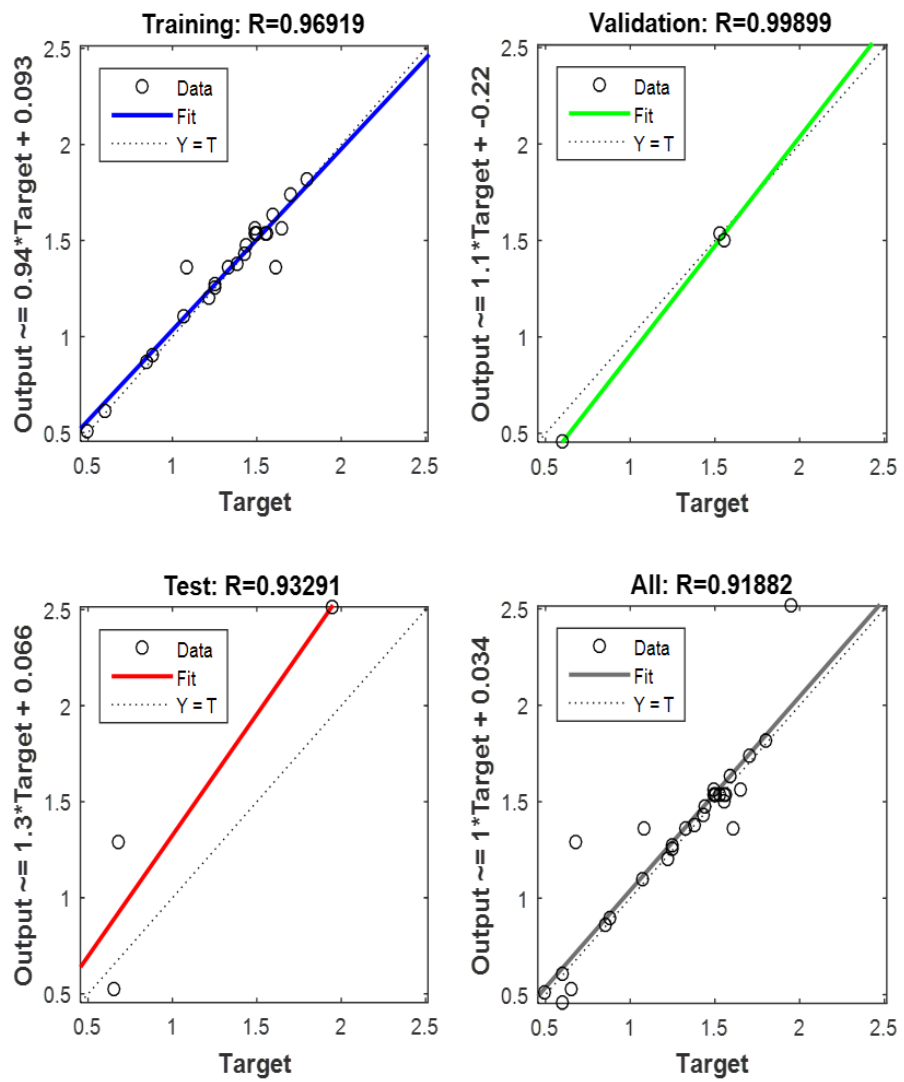

FIGURE 7 Relationship between experimental results and ANN predicted results for $M$.

panel. This problem is related to methanol functional groups $\left(\mathrm{CH}_{2} \mathrm{OH}\right)$ in resin molecule and its confrontation with borate ions (Sean et al., 1999).

Boron compounds not only act as a separating layer on the fiber, but also affect the homogeneous distribution of resin. During the press, it seems that the fibers do not support a continuous line of resin due to the rougher surfaces. Meanwhile, boric acid can have smaller chemical effects on the board compared to other fire retarding agents which have a minimum effect on the roughness (Ustaomer et al., 2008). Adding a fire retardant can decrease the board's strength as a result of the change in the physics and chemistry of the fibers' cell wall (Winandy, 200I), the probability of the delay or acceleration of resin's coagulation due to the effect on resin's $\mathrm{pH}$ during coagulation (Jinxue et al., 20I I), and the contamination of the fibers' surfaces due to the presence of crystal deposited on the fiber which result in weakening of the fiber-fiber contact (Ayrilmis et al., 2012).

Before and during the pressing process, the fire retarding chemicals probably dissolve in the water of the wet fibers and diffuse into the fibers. However, some of the chemicals remain as a powder on the fibers, so that they increase not only the specific surface area of the solids of the system and affect the resin's efficiency
(Ayrilmis, 2007) but also create an interfacial layer between resin and fiber during stress application. When these compounds are added to the fibers smeared with the adhesive, the $\mathrm{pH}$ of the system increases, moisture absorption and the number of accessible hydroxyl groups to create hydrogen bonds decreases, while intensity of the change in viscosity increases. When $\mathrm{pH}$ increases, viscosity increases, wettability of resin declines and quality of its homogeneous distribution on the fibers' surfaces collapses. In these conditions, the combination of the acceleration of resin's coagulation and thermal degradation results in a decrease in the strength (Ayrilmis, 2007).

When the acids in the wood combine with acidic fire retarding agents, they can destroy most formations of the wood such as hemicellulose and cellulose that are the main elements solidifying the wood by the hydrolysis process and can decrease the length of the cellulose molecule and reduce the strength properties in micro dimensions (Popescu and Pfriem, 2020). During this cellulose depolymerization, the increase in the brittleness of the panels treated by acidic fire retarding agents such as ammonium phosphate can be due to the brittleness of the wood fibers as a result of the formation of crystals 

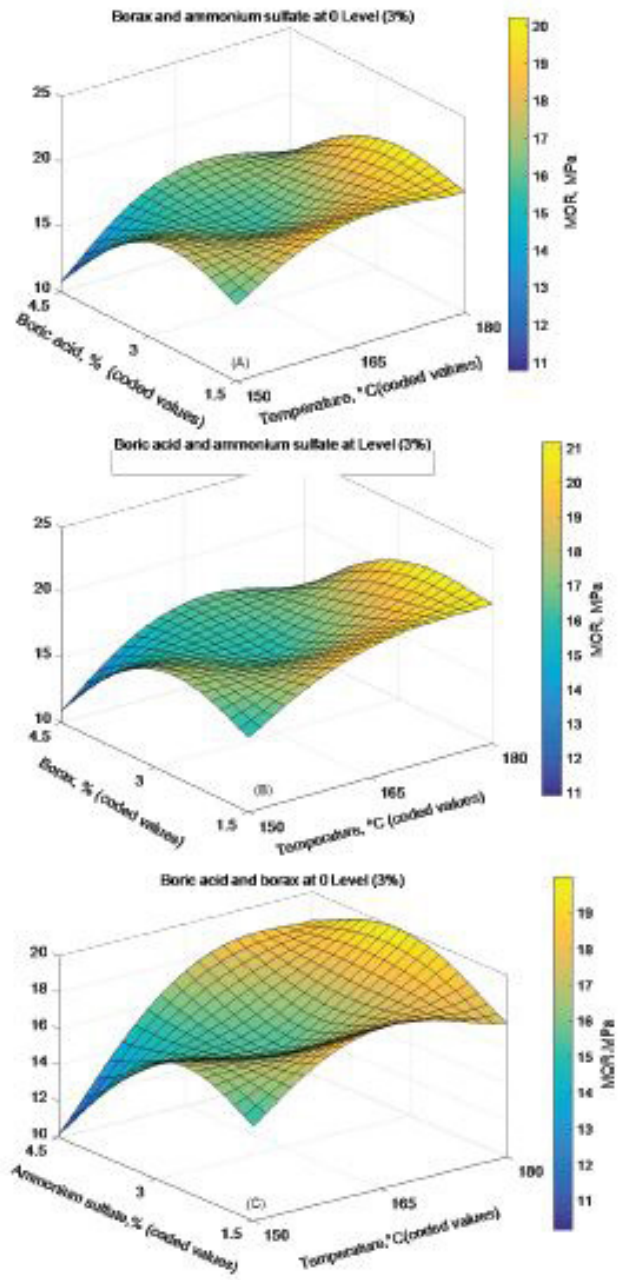

FIGURE 8 The predicted MOR of the fiberboard with different values of $(A)$ boric acid, $(B)$ borax and $(C)$ ammonium sulfate made at different press temperatures.

inside the cell walls or cross connections between hemicellulose and cellulose molecules (Ayrilmis, 2007). During the bending, the connections between the fibers of the upper and lower surface layers that are under pressure and tension are severely affected by the brittleness of the wood fibers and the decrease in the length of cellulose molecules. Also, adding fire retardants composed of $\mathrm{Br}$ salts creates a porous structure in the fiberboard compared to the fiberboards without fire retarding agents (Altuntas et al., 2017). The increase of porosity in the structure decreases the board's strength.

Based on Fig. 9, the mutual effect of the increase in the press temperature and $t$ fire retardant contentd to the fiberboard has resulted in different changes in the ML. In Fig. 9A, the decrease in the press temperature together with an increase in the consumption of boric acid have decreased the $M L$, although this means that the MOR is minimum according to Fig. 8A. Increasing the press temperature results in the rupture of the
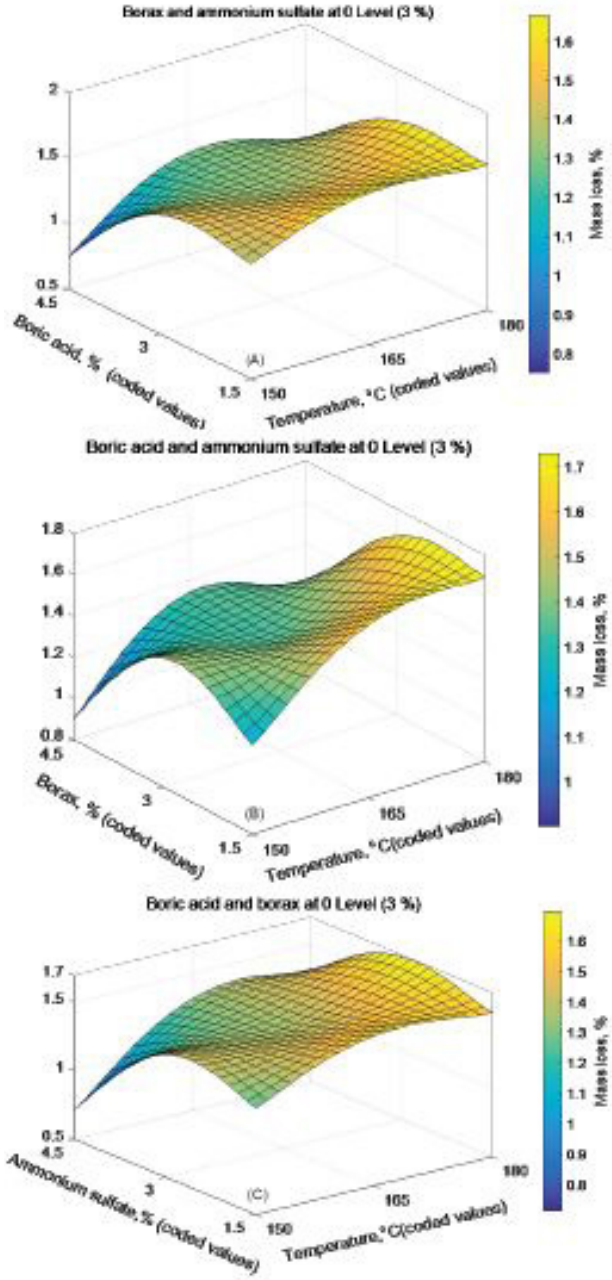

FIGURE 9 The predicted mass loss of the fiberboard with different levels of (A) boric acid, (B) borax and (C) ammonium sulfate made at different press temperatures.

hydrolysable chains of components such as hemicellulose and there will be a higher mass loss in the presence of higher boric acid levels that reduces the $\mathrm{pH}$ as acid compounds are formed due to the hydrolysis reactions created in the wood compnents that are effective in the acceleration of the higher decomposition of the wood. It is evident from the figure that the maximum mass loss occurs when the temperature is maximum while the level of boric acid is limited to $3 \%$. In other words, applying higher temperatures can decrease the mass loss of the board as the level of the fire retardants increase. When fire retardant content is $6 \%$, even applying a maximum press temperature has resulted in a mass loss close to the average level. However, as the press temperature reaches $165 \mathrm{C}^{\circ}$, the mass loss becomes minimum, even less than when the press temperature decreases to minimum level. This is desirable because the mass loss and the subsequent decrease in the MOR will be minimum during the firing. 
Table 3 shows that the mutual effect of the temperature and borax level is significant on the mass loss. Fig. 9B shows that the minimum mass loss has occurred when borax content is $6 \%$ and the board is cured at 165 $\mathrm{C}^{\circ}$, not at minimum levels of press temperature. At the highest press temperature when $3 \%$ borax was used, the mass loss was maximum. However, the mass loss at the minimum temperature and at the average level of borax consumption is almost equal to that when an average press temperature $\left(165 \mathrm{C}^{\circ}\right)$ and $3 \%$ borax are applied. Generally, it can be concluded that in presence of $3 \%$ borax, applying a press temperature of $195 \mathrm{C}$ ${ }^{\circ}$ results in the maximum mass loss while the minimum mass loss occurs in presence of $6 \%$ borax and applying a press temperature of $165 \mathrm{C}^{\circ}$.

According to Fig. 9C, the changes in the mass loss are similar to those in the diagram 9B. As ammonium sulfate is added to $6 \%$ and the temperature decreases to $165 \mathrm{C}^{\circ}$, the mass loss of the specimens reaches the minimum. However, as the press temperature increases to $195 \mathrm{C}$ and an average level of ammonium sulfate is consumed, the mass loss becomes maximum. As the level of ammonium sulfate decreases to $0 \%$ and the press temperature decreases to $165-180 \mathrm{C}$, the mass loss can be minimum. Generally, the addition of all three fire retarding agents has resulted in similar changes in the mass loss with the mutual effect of the temperature, and they have followed a largely equal trend.

When the fire retardants are exposed to the temperature, they still can tolerate pyrolysis and produce more charcoal. According to Abdul Rashid and Murphy (1993), tar and combustible gases are not produced when the surface is exposed to the direct flame. This makes the specimen burn slowly and there will be a lower mass loss per unit time during the direct contact with the flame. It can be expected that while phosphorus and nitrogen compounds show a synergic behavior to create pyrolysis and form more charcoal and water and less combustible gases, boron compounds tend to melt down and create a glass-like barrier on the surface of the wood components stabilizing the charcoal and create a mass transport barrier (Lowden and Hull, 20I3).

The fibers treated by the fire retarding agents need more oxygen to flame and fire harder than the non-treated fibers. In addition, decomposition begins earlier than the non-treated fibers and flaming continues at lower temperatures. Many fire retardants make the flaming slow through this system. Hence, they are directly converted to carbon dioxide and water instead of forming the intermediate flammable tar. Due to the decline of the decomposition temperature, the speed of charring the fibers treated by fire retarding compounds may be more than the non-treated fibers. The increase in the charcoal level can produce an extra isolated surface and prevent it from emission of flammable gases in the presence of the flame. According to the studies conducted, it became clear that as the level of fire retarding agents such as borax increases during TG test, the level of the flammable gases decreases in the compound (Baysal, 2002). Exothermic reactions occurring during cellulose firing result in the formation of flammable gases and create less charred residues (Popescu and Pfriem, 2020). In the presence of the fire retardants, not only there is a lower exothermic temperature, but also other exothermic reactions related to two other substances making the cell wall are also cancelled out.

The fire retarding chemicals decrease the pyrolysis temperature and the mass loss decreases due to the increase in the carbonization. As a result of the increase in carbonization, fewer gases are also emitted. The decrease in the mass loss is related to the increasing the chemical effects on the panel's resistance to fire and the positive effect against firing. As the fire retardant content increases, the treated specimens burn very slowly, because the ratio of the oxygen required during the flammability test decreases. In other words, it seems that the addition of fire retarding agents is effective. Hence, as fire retardant content increases, the rate of firing decreases due to the decrease in the oxygen ratio and as a result, the mass loss decreases.

\section{CONCLUSIONS}

This study focused on the ANN modeling of the effect of adding fire retarding chemicals and press temperature on the MOR and ML during the firing of the medium density fiberboard (MDF) connected with UF resin.

The developed artificial neural network is suitable for modeling the MOR together with the fire retarding properties of the fiberboard using the press temperature and chemical fire retarding agents at different levels.

The artificial neural network is suitable to examine the effect of the press temperature and the level of boric acid, borax, and ammonium sulfate as the fire retarding agents on the MOR and mass loss of the fiberboard during the firing.

The results of the study showed that MOR changes significantly as the press temperature and the type and level of the fire retardants change. A higher press temperature has resulted in the increase in both MOR and ML of the boards. 
As the press temperature increased, the negative effect of adding the fire retarding agents on the MOR decreased, while at a low press temperature, the negative effect of the fire retardants was maximum.

A reverse relation was observed between the changes in the mass loss of the fiberboard during the firing test and the MOR, so that as the mass loss increased, the MOR decreased. However, when higher press temperatures was applied, the negative effect of the board's mass loss on the bending properties of the board could be decreased. In other words, although the mass loss of the board decreased when lower temperatures were applied, the minimum values of MOR of the boards were obtained when the maximum level of the fire retardants was used.

The changes in the MOR and mass loss of the boards were similar in presence of all types of the fire retardants added to the fiberboard.

\section{REFERENCES}

ABDUL RASHID, A. M.; MURPHY, R. J. Pyrolysis and heat release of inorganic flame retardants. Journal of Tropical Forest Science. v. 5, n. 3, p. 322-336, 1993.

AKYUZ, I.; OZSAHIN, S.; TIRYAKI, S.; AYDIN, A. An application of artificial neural networks for modeling formaldehyde emission based on process parameters in particleboard manufacturing process. Clean Technologies and Environmental Policy, v. 19, n. 5, p. |449-|458, 2017.

ALTUNTAS, E.; NARLIOGLUE, N.; ALMA, M. H. Investigation of fire, thermal, and mechanical properties of zinc borate and synergic fire retardants on composites produced with PPMDF wastes. BioResources. v. I2, n. 4, p. 697I-6983, 2017.

ANDRE, N.; CHO, H. W.; BAEK, S. H.; JEONG, M. K.; YOUNG, T. M. Prediction of internal bond strength in a medium density fiberboard process using multivariate statistical methods and variable selection. Wood Science and Technology. v. 42, n. 7, p. 52I-534, 2008.

ARSENAULT, R. D. Fire-retardant particleboard from treated flakes. Forest Products Journal. v. I4, n. 6, p. 33-9, 1964.

ASHTIYANI, H.; SHAHSAVARI, P. Prediction of hot deformation behavior of AA2030 using artificial neural networks. Journal of Engineering of Mechanic, v. 47, n. 2, p. 79$86,2018$.

AYRILMIS, N.; AKBULUT, T.; DUNDAR, T.; WHITE, R.H.; MENGELOGLU, F.; BUYUKSARI, U.; CANDAN, Z.; AVCI, E. Effect of boron and phosphate compounds on physical, mechanical, and fire properties of wood-polypropylene composites. Construction and Building Materials, v. 33, p. 63-69, 2012.

AYRILMIS, N. Effect of fire retardants on internal bond strength and bond durability of structural fiberboard. Building and Environment. v. 42, n. 3, p. 1200-1206, 2007.
BARDAK, S. Predicting the impacts of various factors on failure load of screw joints for particleboard using artificial neural networks. BioResources. v. I3, n. 2, p. 3868-3879, 2018.

BARDAK, S.; TIRYAKI, S.; NEMLI, G.; AYDIN, A. Investigation and neural network prediction of wood bonding quality based on pressing conditions. International Journal of Adhesion and Adhesives. v.68, p. 15-123, 2016.

BATTEGAZZORE, D.; ALONGI, J.; DURACCIO, D.; FRACHE, $A$. Reuse and valorisation of hemp fibres and rice husk particles for fire resistant fibreboards and particleboards. Journal of Polymers and the Environment. v. 26, n. 9, p. $3731-3744,2018$

BAYANI, S,; TAGHIYARI, H. R,; PAPADOPOULOS, A. N. Physical and mechanical properties of thermally-modified beech impregnated with silver nano- suspension and their relationship with the crystallinity of cellulose. Polymers, v. II, n. I538, p. 8I-94, 2019.

BAYSAL, E. Determination of oxygen index levels and thermal analysis of scots pine (Pinus sylvestris L.) impregnated with melamine formaldehyde-boron combinations. Journal of Fire Sciences. v. 20, n. 5, p. 373-389, 2002.

BEKHTA, P.; BRYN, O.; SEDLIACIK, J.; NOVAK, I. Effect of different fire retardents on birch plywood properties. ACTA Facltatis Xyloloiae Zvolen, v. 58, n. I, p. 59-66, 2016.

BOGA, A. R.; OZTURK, M.; TOPCU, I. B. Using ANN and ANFIS to predict the mechanical and chloride permeability properties of concrete containing GGBFS and CNI. Composites: Part B. v. 45, p. 688-696, 2013.

CANAKCI, A.; OZSAHIN, S.; VAROL, T. Modeling the influence of a process control agent on the properties of metal matrix composite powders using artificial neural networks. Powder Technology. v. 228, p. 26-35, 2012.

EN 326-I. Sampling, cutting, and inspection. Part I.

EN 310. 1993. Determination of bending strength and modulus of elasticity. European Committee for Standardization. Wood-based panels.

FERLE L.C., DOS SANTOS, G.H.; MESQUITA, L. M. R. Mechanical properties of wood based panels with and without fire retardants. Proceedings of the Ist Iberic Conference on Theoretical and Experimental Mechanics and Materials / I I th National Congress on Experimental Mechanics. Porto/Portugal 4-7 November 2018. Ed. J.F. Silva Gomes. INEGI/FEUP (20I8); ISBN: 978989-20-877I-9; pp. 767-776, 2018.

GUOLIANG, J.; FUGUE, L.; QINGHUA, L.; HUIQU, L.; ZHI, L. Prediction of the hot deformation behavior for Aermet 100 steel using an artificial neural network. Computer and Material Science. v. 48, n. 3, p. 626-632, 2010.

ISO I1925-3. 1997. Cor. I (1998) Reaction to fire tests. Ignitability of building products subjected to direct impingement of flame. Part III: multi-source test. 
ISWANTO, A.; FEBRIANTO, F;; Had, Y.; RUHENDI, S. HERMAWAN, D. The Effect of Pressing Temperature and Time on the Quality of Particle Board Made from Jatropha Fruit Hulls Treated in Acidic Condition. Makara Journal of Technology, v. I7, n. 3, p. I45-I5I, 2013.

JINXUE, J.; YONGLIN, Y.; CHENG, L.; JIANZHANG, L. Effect of three boron flame retardants on thermal curing behavior of urea formaldehyde resin. Journal of Thermal Analysis and Calorimetry, v. 105, p. 223-228, $201 \mathrm{I}$.

LeVAN, S. L.; WINANDY, J. E. Effects of fire retardant treatments on wood strength: a review. Wood and Fiber Science. v. 22, n. I, p. I|3-131, 1990.

LOREDO, N. U.; BERMEJO, J. S. Enhanced flame retardancy of flaxbio-composites for the construction market. Journal of Facade Design and Engineering v. 4, 67-76. 2016.

LOWDEN, L. A.; HULL, T. R. Flammability behavior of wood and a review of the methods for its reduction. Fire Science Reviews. v. 2, n. 4, p. I-19, 2013.

MA, X.; WU, Y. Z.; ZHU, H. L. The fire-retardant properties of the melamine-modified urea-formaldehyde resins mixed with ammonium polyphosphate. Journal of Wood Science, v. 59, p. 419-425, 2013.

MANONMANI, K.; MURUGAN, N.; BUVANASEKARAN, G. Effect of process parameters on the bead geometry of laser beam welded stainless steel sheets. International Journal of Advanced Manufacturing Technology. v. 32, n. I II2, p. I |25-I I33, 2007.

MANTANIS, G. I.; MARTINKA, J.; LYKIDIS, C.; SEVCIK, L. Technological properties and fire performance of medium density fiberboard (MDF) treated with selected polyphosphate-based fire retardants. Wood Material Science and Engineering, I-9. 2019.

OZDEMIR, F.; TUTUS, A. Effect of fire retardants on the combustion behavior of high -density fiberboard. BioResources. v. 8, n. 2, p. 1667-1674, 2013.

POPESCU, C. M.; PFRIEM, A. Treatments and modification to improve the reaction to fire of wood and wood based productsAn overview. Fire and Materials, v. 44, p. I00- I I I, 2020.

PALACIOS, P. D.; FERNANDEZ, F. G.; GARCIA-IRUELA, A.; GONZALEZ-RODRIGO, B.; ESTEBAN, L. G. Study of the influence of the physical properties of particleboard type $\mathrm{P} 2$ on the internal bond of panels using artificial neural networks. Computers and Electronics in Agriculture. v. 155, p. 142-149, 2018.

PHANIRAJ, P. M.; LAHIRI, K. A. The applicability of neural network model to predict flow stress for carbon steels. Journal of Material Process and Technology. v. 2, n. I4I, p. 219-227, 2003.

REIS, P. C. D.; SOUZA, A. L.; REIS, L. P.; CARVALHO, A. M. M. L.; MAZZEI, L.; REGO, L. J. S.; LEITE, H. G. Artificial neural network to estimate the physical-mechanical properties of amazon second cutting cycle wood. Maderas. Ciencia y Tecnologia, v. 20, n. 3, p. $343-352,2018$.
SEAN, T.; BRUNETTA, G.; COTE, F. Protection of oriented strandboard with borate. Forest Products Journal. v. 49, n. 6, p. 47-5I, 1999.

UNER, B.; OLUN, C. The effect of hardner on adhesive and fiberboard properties. Wood Research, v. 62, n. I, p. $27-$ 36, 2017.

UNER, I. H.; DEVECI, I.; BAYSAL, E.; TURKOGLU, T.; TOKER, H.; PEKER, H. Thermal analysis of Oriental beech wood treated with some borates as fire retardants. Maderas. Ciencia y tecnologia, v. I8, n. 2, p. 293 - 304, 2016.

USTAOMER, D.; USTA, M.; HIZIROGLU, S. Effect of boron treatment on surface characteristics of medium density fiberboard (MDF). Journal of Materials Processing Technology. v. 199, p. 440-444, 2008.

De VEAUX, R. D.; UNGAR, L. H. A Brief Introduction to Neural Networks.<http://www.cis.upenn.edu/ ungar/ Datamining/Publications/nnet-intro.pdf $>$ (accessed 12.05.14, 1994.

WANG, Q. W.; LI, J.; WINANDY, J. E. Chemical mechanism of fire retardance of boric acid on wood. Wood Science and Technology, v. 38, p. 375-389, 2004.

WINANDY, J. E. Thermal degradation of fire-retardant-treated wood:Predicting residual service life. Forest Products Journal. v. 5 I, n. 2, p. 47-54, 200 I.

WINANDY, J. E.; RIVER, B. H. Evaluation of a method for testing adhesive preservative compatibility. Forest Products Journal, v. 36, n. I, p. 27-32, 1986.

WATANABE, K.; KORAI, H.; MATSUSHITA, Y.; HAYASHI, T. Predicting internal bond strength of particleboard under outdoor exposure based on climate data: comparison of multiple linear regression and artificial neural network. Journal of Wood Science. v. 6I, p. I5I-I58, 2015.

WINANDY, J. E.; KRZYSKI, A. M. Thermal degradation of wood fiber during hot-pressing of MDF composites: part I. relative effects and benefits of thermal exposure. Wood and Fiber Science, v. 39, n. 3, p. 450 - 46I, 2007.

WU R. H.; LIU, J. T.; CHANG, H. B.; HSU, T. Y.; RUAN, X. Y. Prediction of the flow stress of $0.4 \mathrm{C}-1.9 \mathrm{Cr}-1.5 \mathrm{Mn}-1.0 \mathrm{Ni}-$ 0.2 Mo steel during hot deformation. Journal of Material Processing Technology. v. II6, n. 2-3, 21 I-2।8, 200 I.

YANG, W.; QING, Y. Effect of typical boron compounds on the thermal degradation and combustion properties of Phyllostachys pubescen. Engineering Science, v. 16, n. 4, p. 5I-55, $20 \mid 4$.

ZHAO, J.; DING, H.; ZHAO, W.; Huang, M.; WEI, D.; JIANG, Z. Modelling of the hot deformation behavior of a titanium alloy using constitutive equations and artificial neural network. Computer and Material and Science. $n$. 92 , p. 47-56, 2014 